\title{
Generalised Mottled Pigmentation in Chediak-Higashi Syndrome in a Child-An Uncommon Manifestation
}

\section{(1) Sumit Sen, (1) Subhadeep Mallick, (1) Surabhi Sharma, (1) Arpita Hati}

Institute of Post-Graduate Medical Training and Research and Seth Sukhlal Karnani Memorial Hospital Hospital, Clinic of Dermatology, West Bengal, India

\section{ABSTRACT}

Observation: Chediak-Higashi syndrome is an extremely rare autosomal recessive disorder characterized by partial oculo-cutaneous albinism, recurrent bacterial infection and abnormally large granules in leukocytes and other cells. Here we report a case who had presented with generalised mottled pigmentation.

Keywords: Chediak-Higashi syndrome, Autosomal recessive disorder, Albinism, Photophobia

\section{Introduction}

Chediak-Higashi syndrome (CHS) is a rare autosomal recessive disorder characterized by partial oculo-cutaneous albinism, recurrent bacterial infection, bleeding diathesis, nystagmus, photophobia. There are abnormally large granules in leukocytes [1]. It presents usually in childhood and patient may develop severe anemia, bleeding manifestation, organomegaly, overwhelming bacterial infection leading to death [2]. Here we report a case who presented with diffuse hypopigmentation. This case is reported due to its extreme rarity. Less than 500 cases have been reported worldwide [3].

\section{Case Report}

A10-year-old boy presented in the paediatrics outpatient department (OPD) with recurrent cough, respiratory distress and fever from one year of age and was referred to Dermatology OPD for abnormal pigmentation of skin. His younger brother had similar disorder and had died at an age of 6 years. There is history of consanguineous marriage between his parents.
Examination revealed anthropometrically normal for age male. He was pale and febrile. On cutaneous examination there was diffuse mottled hypo and hyper pigmentation over anterior trunk, neck, upper and lower extremities (Figure 1) and over posterior trunk, neck, upper and lower extremities (Figure 2) and dark gray sparse hair with mottled hypo and hyper pigmentation over face (Figure 3). In eyes there was no nystagmus, no photophobia and no albinism. Examination of the abdomen revealed soft abdomen with liver 4 $\mathrm{cm}$ below right costal margin, spleen $3 \mathrm{~cm}$ below left costal margin. First and second heart sound were normal. Bilateral vesicular breath sounds with no added sounds were present. History of decortications, done on left side for empyema thoracis was reported by mother of the child. The findings of the laboratory investigations were as follows: hemoglobin $(\mathrm{Hb}): 10.2 \mathrm{gm} / \mathrm{dL}$, total leukocyte count (TLC): $6200 / \mathrm{mm}^{3}$ (neutrophils 15\%, lymphocytes 75\%, eosinophils 2\%, monocytes 8\%), platelets: 1.82 lakhs (done on 05.11.18). Repeat test was performed on 06.11 .18 and it showed $\mathrm{Hb}: 11.6 \mathrm{gm} / \mathrm{L}$, TLC: $6200 / \mathrm{mm}^{3}$ (neutrophils 25\%, lymphocytes 65\%, eosinophils $2 \%$, monocytes $8 \%$ ), platelets 2 lakhs, leukocytes (neutrophils and monocytes) showed giant granules on peripheral blood smear 
stained with hematoxylin and eosin stain at 100x (Figure 4). IgG: 447 mg/dL, IgM: 18.7 mg/dL, IgA: 62 mg/dL. T Iymphocytes numbered 1846 cells/microlt, CD4+ T cells: 969 cells/microlt, CD8+ T cells: 771 cells/microlt, CD4/CD8 1026, CD19+ cells, CD20+ cells $14.37 \%$ of the lymphocytes. His parents did not give consent for skin biopsy. Based on these findings a diagnosis of CHS was made.

\section{Discussion}

CHS was first described by Bequez Cesar in 1934. Further reported by Chediak in 1952 and Higashi in 1954 the hematological features were emphasized [4].

It is a rare autosomal recessive disorder with mutation in a single gene LYST localized to 1q42-43 [5]. The basic pathology is

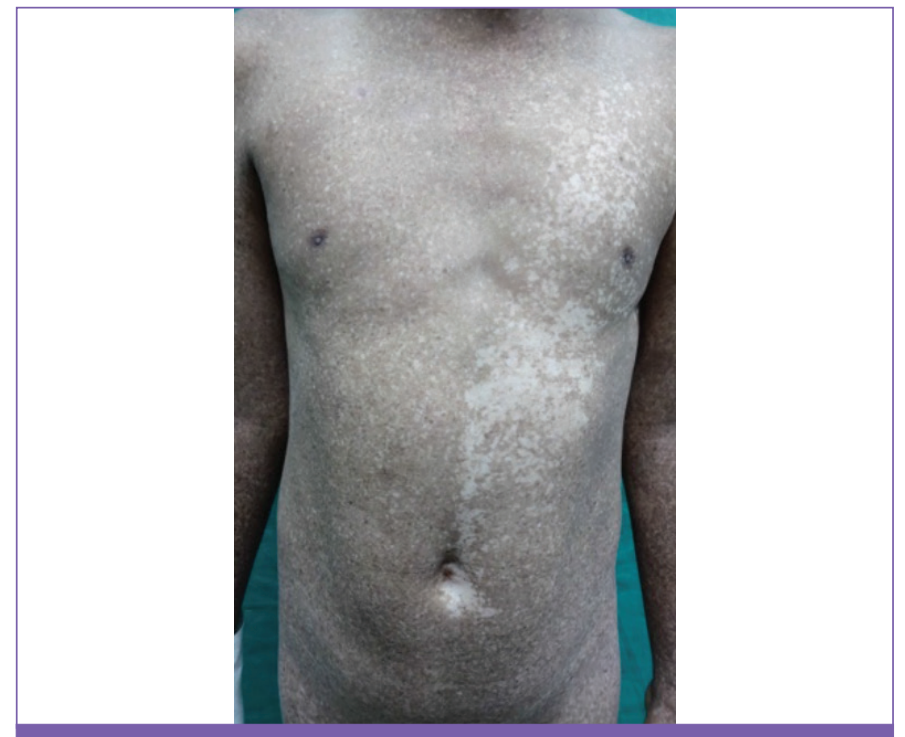

Figure 1. Diffuse mottled hypo and hyper pigmentation over anterior trunk, neck, upper and lower extremities

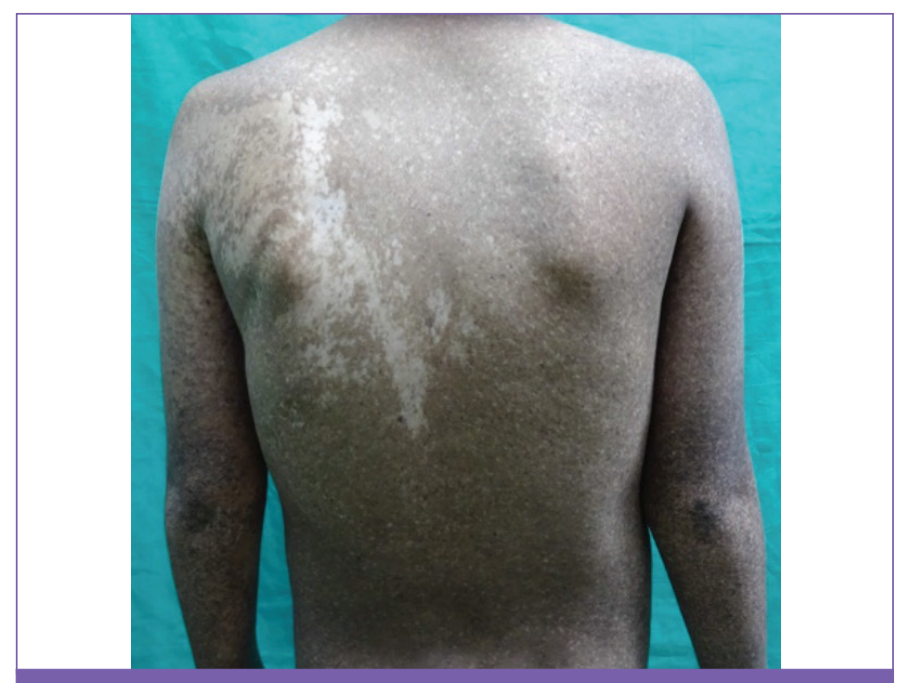

Figure 2. Diffuse mottled hypo and hyper pigmentation over posterior trunk, neck, upper and lower extremities defective phagolysosome fusion [6], defects in T cell cytotoxicity, in natural killer cell activity as well as in chemotaxis all leading to increased susceptibility to infection. The giant granules are present in neutrophils, monocytes, lymphocytes, platelets and melanocytes [7]. In melanocytes there are giant melanosomes which prevent even distribution of melanin. Hypopigmentation occurs because the melanosomes within keratinocytes are found within a relatively few large lysosomes rather than dispersed throughout the cell cytoplasm leading to diffuse hypopigmentation. Sparse gray hair occurs associated with pigment clumping [8]. Light microscopic features of skin sections show normal findings. Fontana-Masson stain shows sparse melanin granules, some of which are grouped and others of which are larger than normal.
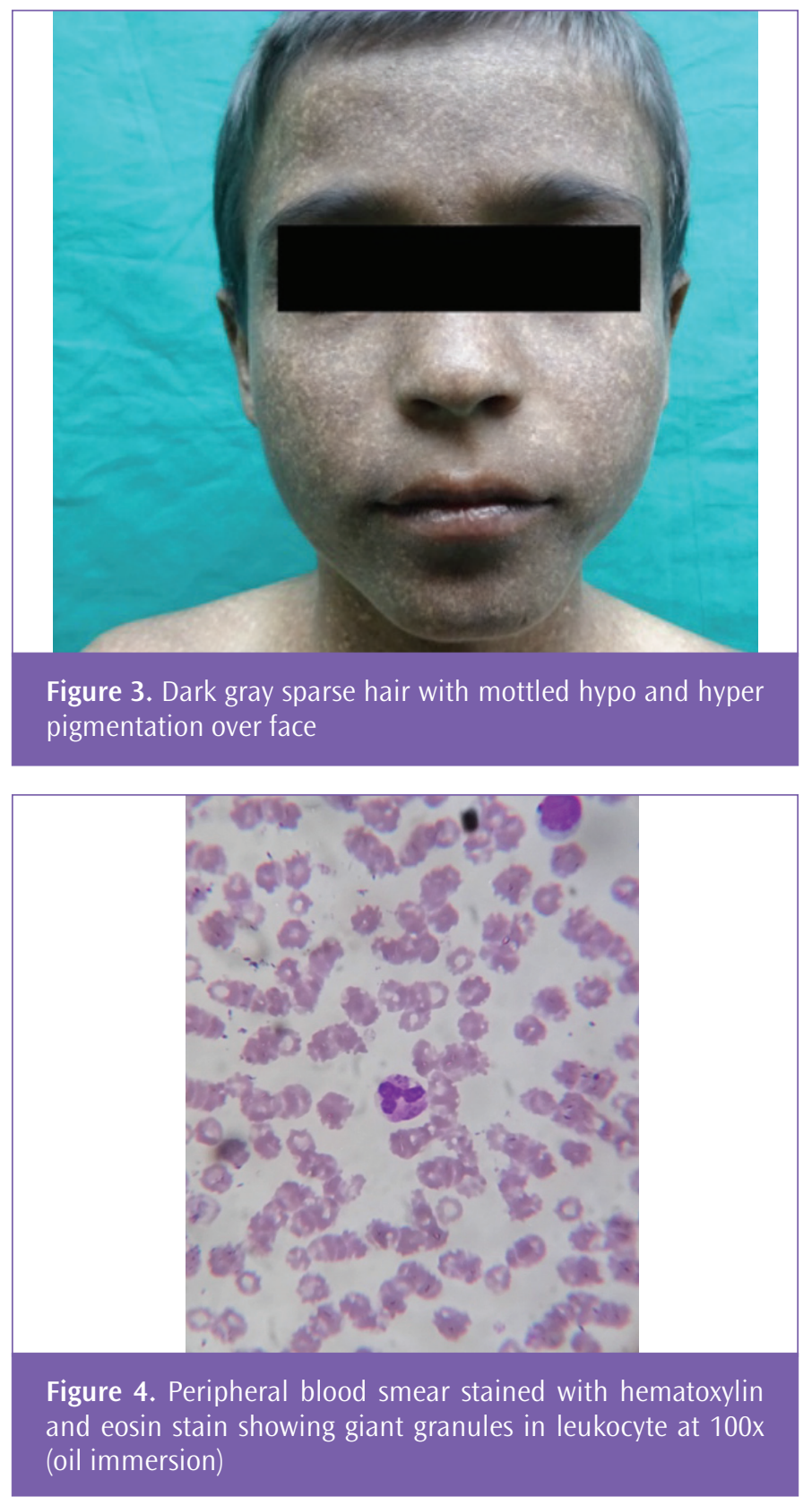
Similar large, irregularly shaped melanin granules are scattered in the upper dermis within melanophages [9]. 50-70\% of patients with CHS develop an accelerated phase characterized by fever, jaundice, hepatosplenomegaly, Iymphadenopathy, pancytopenia, coagulopathy, neurological abnormalities and diffuse mononuclear cell infiltrates into the organs. The accelerated phase may occur shortly after birth or several years later which may be fatal if untreated.

Differential diagnosis of CHS includes Griscelli syndrome and Hermansky Pudlak syndrome; both these lacks giant granules in neutrophils. There is also an entity called pseudo CHS syndrome where abnormal granules are seen only in granulocytes in some cases of acute myeloid leukemia [10].

Our case is important because the child had only diffuse mottled hypo and hyper pigmentation and giant granules in peripheral blood smear with a positive family history which can be a variant of CHS. Any child presenting with recurrent pyogenic infection with features of partial oculocutaneous albinism should thoroughly be screened to rule out CHS as it is progressively fatal, rare disease and patient may enter into the accelerated phase.

\section{Ethics}

Informed Consent: Patient's parents had given consent for not disclosing the name of the child.

Peer-review: Internally peer-reviewed.

\section{Authorship Contributions}

Surgical and Medical Practices: S.S., S.M., S.S., A.H., Concept: S.S., S.M., S.S., A.H., Design S.S., S.M., S.S., A.H., Data Collection or Processing: S.S., S.M., S.S., A.H., Analysis or Interpretation: S.S., S.M., S.S., A.H., Literature Search: S.S., S.M., S.S., A.H., Writing: S.S., S.M., S.S., A.H.
Conflict of Interest: No conflict of interest was declared by the authors.

Financial Disclosure: The authors declared that this study received no financial support.

\section{References}

1. Shende A. Disorders of White blood cells. In: Lanzkowsky P, editor. Manual of Pediatric Hematology and Oncology, 4th ed. California: Elsevier; 2005. p. 230-231.

2. Dhawle MS, Joshi AR, Awari MM, Rathod SG, Bindu RS. Chediak-Higashi syndrome: A case report. International Journal of Current Medical And Pharmaceutical Research 2016;2:524-526.

3. Rudramurthy P, Lokanatha H. Chediak-higashi syndrome: A case series from Karnataka, India. Indian J Dermatol 2015;60:524.

4. Skubitz KM. Qualitative disorder of leukocytes. In: Lee GR, Foester J, Lukens J, Paraskevas F, Greer JP, Rodgers GM, editors. Wintrobe's Clinical Hematology, 12th ed. Philadelphia: Williams and Wilkins; 2009. p. 1548-1564.

5. Barrat FJ, Anloge L, Pastural E, Lagelouse RD, Vilmer E, Cant AJ, Weissenbach J, Le Paslier D, Fischer A, de Saint Basile G. Genetic and physical mapping of CHS on chromosome. Am J Hum Genet 1996;59:625-632.

6. Kumar V, Abbas AK, Fausto N, Aster JC. Acute and Chronic Inflammation. In: Kumar V, Abbas AK, Fausto N, Aster JC, editors. Robbins and Cotran Pathologic Basis of Disease, 8th ed. Philadelphia: Elsevier; 2009. p. 55.

7. Barak Y, Nir E. Chediak-Higashi syndrome. Am J Pediatr Hematol Oncol 1984;9:42-55.

8. Blume RS, Wolff SM. The Chediak-Higashi syndrome: studies in four patients and a review of the literature. Medicine 1972;51:247-280.

9. Carillo-Farga J, Gutierrez-Palomera G, Ruiz-Maldonado R, Rondan A, Antuna S. Giant cytoplasmic granules in Langerhans' cells of Chédiak-Higashi syndrome. Am J Dermatopathol 1990;12:81-87.

10. Rao S. Kar R. Saxena R. Pseudo Chediak-Higashi anomaly in acute myelomonocytic leukemia. Indian J Pathol Microbiol 2009;52:255-256. 